\title{
Job satisfaction of registered nurses in a community hospital in the Limpopo Province in South Africa
}

\author{
HPP Kekana \\ MCur Graduate, University of Pretoria
}

\author{
EA du Rand \\ Senior Lecturer, Department of Nursing Science, University of Pretoria \\ Prof NC van Wyk \\ Head: Department of Nursing Science, University of Pretoria
}

Correspondence address:

Prof NC van Wyk

Department of Nursing Science

University of Pretoria

PO Box 677

Pretoria, 0001

Tel : (012) 354-1980

Fax:(012) 354-1682

E-mail :nvanwyk@medic.up.ac.za

Abstract: Curationis 30(2): 24-35

Nurses are confronted daily with the demands of an increased workload and insufficient facilities in the public healthcare sector in South Africa. The purpose of the study was therefore to determine the degree of job satisfaction of registered nurses in a community hospital in the Limpopo Province of South Africa.

A quantitative descriptive design was used to meet the objectives of the study. The population was not sampled because of the small size of it. All the registered nurses who had one or more years experience in this hospital were included in the study.

A self-administered questionnaire was used to collect data from them regarding the working conditions in the hospital including the emotional and social climate. The questionnaire was based on an instrument developed by Humphries and Turner (1989:303) to determine the degree of job satisfaction of nursing staff in a unit for elderly mentally retarded patients. The findings indicated that the majority of the respondents were dissatisfied about the working conditions and emotional climate in the hospital while they were fairly satisfied with the social climate.

The workload and degree of fair remuneration, under the working conditions, were the most highly rated as dissatisfying ( $83 \%$ of the participants) while under the emotional climate they indicated that the pressure under which they worked was highly dissatisfying ( $82 \%$ of the participants).

As the results indicated that the social climate was satisfactory; having a best friend at work and the chance to help other people while at work, were rated positively by $88 \%$ and $76 \%$ of the participants respectively.

Recommendations made included that managers have to show the staff that their best interest is their number one concern. Leaders have to be available for the staff and being willing to buffer the stress caused by increased workload and insufficient resources. Greater visibility of supervisory staff should therefore be encouraged.

\section{Introduction}

Job satisfaction derives from individual nurses' perception of various aspects of their work and is related to their orientation towards their work. It is influenced by the values the individual assumes in a work situation and there appears to be a connection between job satisfaction, the self-concept of the individual and his/her career orientation
(Bester, Richter \& Boshoff, 1997:59).

Research done on this subject has shown that various factors contribute to satisfaction in work settings. In their study on exploring sources of satisfaction in the $1990 \mathrm{~s}$, Tovey and Adams (1999:150) found that nurses are not a homogeneous group with regard to job satisfaction. In order to develop a 
more accurate picture, it may be necessary to develop different measures to determine the level of job satisfaction for different grades and it is equally important to recognize that nurses' levels of satisfaction are becoming more varied due to increasingly varied work environments. Good relationships between members of staff, sufficient numbers of staff and the right skills mix, however, contribute to job satisfaction of different levels of staff (Adam \& Bond, 2000:541).

In her article on "The migration of nurses and midwives", Geyer (2001:27) reports that reasons for dissatisfaction given in the DENOSA (Democratic Nursing Organisation of South Africa) project were low salaries, lack of competitive incentives in the public service, work pressure due to long working hours, poorly resourced hospitals and the high nurse-to-patient ratio in South Africa. She further reported that the problem is complex and should be seen against the background of other initiatives that have taken place in South Africa, such as the government's decision to right-size the public service and the offering of voluntary severance packages to staff. The public healthcare sector has therefore been left with limited staff and frozen posts (Geyer, 2001:27).

The retaining of a well qualified nursing cadre is of utmost importance not only to maintain the public's confidence in the nursing profession, but also in healthcare in general (Fletcher, 2001:330). One way of curbing the resignation of nurses is by addressing their dissatisfaction with working conditions. The turnover of nurses increases when job satisfaction decreases. The resignation of nurses contributes to a higher workload for those who remain and eventually leads to their job dissatisfaction with the result that they too consider leaving the profession.

The community hospital that was selected for this research was at the time of the study no exception. The nurses complained about the working conditions in the hospital and many threatened to ask for transfers to other hospitals. The aim of this study was therefore to determine the degree of job satisfaction among the registered nurses of the hospital regarding their working conditions and the general emotional and social working climate in the hospital.
Through the identification of problems recommendations could be made in relation to an appropriate employee assistance programme to promote the retention of nurses at the hospital.

\section{Definition of key concepts}

The following definitions are applicable to the study:

Job satisfaction is defined as the degree of positive affect a person has towards his/her job and is determined by the characteristics of both the individual and the job (Adam \& Bond, 2000:538). The satisfaction increases with the degree of enjoyment of the job by the person, the level of autonomy associated with the job and the professional status thereof (Shader, Broome, Broome, West \& Nash, 2001:210). Job satisfaction relates to the working conditions, emotional and social working climate.

Working conditions reflect the milieu in which a person has to perform his/her job. It relates thus to the individual's perception of the conditions. Various factors may influence it such as workload, salary, fringe benefits, adequate resources, professional growth opportunities and the amount of challenge in one's job (Shader et al., 2001:215).

Emotional working climate refers to the level of autonomy nurses experience, their self-concept as nurses and commitment to the nursing profession (Bester et al., 1997:60). A huge workload can be coped with in cases of a high level of commitment by nurses.

Social working climate refers to the interaction between persons at work, the group cohesiveness and the general team spirit. Nurses prefer to work in an environment with good team spirit and where they can communicate freely with their nursing and medical colleagues (Adam \& Bond, 2000:538).

\section{Research methodology}

A quantitative, descriptive design was used to observe, describe and document the degree of job satisfaction by the participants. A questionnaire was used to determine the areas of satisfaction and dissatisfaction. The study population consisted of 39 registered nurses located in various units of a selected community hospital with 105 beds. The whole population was used; questionnaires were distributed to 39 potential participants. All the nurses had had clinical experience in all the wards/units of the hospital. Thirty-four (34) nurses ( $87 \%$ of the 39 potential participants) submitted completed questionnaires.

\section{The questionnaire as the data collection tool}

A self-administered questionnaire was used that consists of 3 sections, namely the working conditions, emotional and social working climate. A four point Likert-scale allowed the participants to indicate whether they were extremely dissatisfied, dissatisfied, satisfied or extremely satisfied with aspects regarding their working conditions and the emotional and social climate in the hospital. Statements such as "The degree of fair payment in relation to my inputs" (working conditions); "The opportunity to develop new and better ways of doing things" (emotional climate); and "The amount of support and guidance provided by my supervisor" (social climate) were included.

Two sections of the questionnaire, namely the working conditions and emotional working climate are identical copies of an instrument that was used in 1989 to determine the job satisfaction of nursing staff in a unit for elderly mentally retarded patients by Humphries and Turner (1989:301-303). The reliability of the instrument was tested by calculating the internal consistency using the Cronbach Alpha Coefficient. The working conditions' satisfaction scale was 0,87 and that of the emotional climate was 0,93 which are acceptable reliability levels (Humphries \& Turner, 1989:303).

The third section in which the social climate among the nurses in the hospital is reflected was added to the questionnaire. It was compiled after a thorough literature review. It includes aspects regarding support given by colleagues and managers.

The questionnaire made provision for biographical and general data such as the participants' age, gender, marital status and actual hours of work per week.

\section{Pilot study}

A pilot study was conducted at another community hospital in the same district 
so that adjustments could be made to the tool if necessary. Two registered nurses took part in the pilot study; both had one or more years' work experience in that particular hospital. Following the pilot study, adjustments were made to the section on biographical data.

\section{Process of data collection}

After the approval by the Department of Health and Welfare of the Limpopo Province and the Superintendent of the hospital was obtained, meetings were arranged with the registered nurses at different times to accommodate the staff on day and night duty as well as those that were on leave. Two meetings were held with the nurses on night duty, four with the nurses on day duty and two with the nurses on leave in order to ensure that all the registered nurses were invited to take part in the research.

The study was explained to them and an opportunity to ask questions was given. They were then invited to participate. Informed consent was obtained from the nurses who were willing to take part in the research. The participants were assured of anonymity by having it explained to them that coding of questionnaires would be done using numbers instead of names so that they would not be identified, and that only figures would be used instead of words when they completed the questionnaires. The participants were informed that participation was voluntary and that no remuneration for participating would be given.

The questionnaires were then distributed to them, further explanation on the completion of it was given and questions were invited. It was arranged that the competed questionnaires should be placed in a container at an agreed-upon venue by a set date.

\section{Ethical aspects}

The Faculty of Health Sciences Research Ethics Committee, University of Pretoria approved the methodology of the study and permission to conduct the study was obtained from the Department of Health and Welfare of the Limpopo Province and the Superintendent of the selected hospital.

\section{Presentation and interpretation of the data} The data is presented, discussed and interpreted simultaneously under the sections, biographical information and satisfaction/dissatisfaction with working conditions including emotional and social climate in the hospital.

\section{Biographical information}

The majority of the participants, namely $76 \%$ (26 persons) were older than 35 years that qualifies them to be called the 'Baby Boomers'; persons being born between 1946 and 1964. According to Kupperschmidt (2001:572) this group of people most likely wants to be appropriately compensated for their efforts, prefers to work independently, usually does not mind to work long hours, but dislikes performance appraisals. The younger group of the participants ( $24 \%$ of 34 participants), called the 'Generation X'ers' born between 1965 and 1975, on the other hand usually views the work place as an opportunity for personal growth and places a high premium on further studies (Kupperschmidt, 2001:573). Different fringe benefits will therefore be needed to ensure job satisfaction of such a diverse group of people.

The group of participants reflects nursing as a predominantly female profession as only 2 participants were men. With $68 \%$ of the total group of participants $(n=34)$ being married, it can be assumed that the majority of the

Figure 1: Professional qualifications $(n=34)$

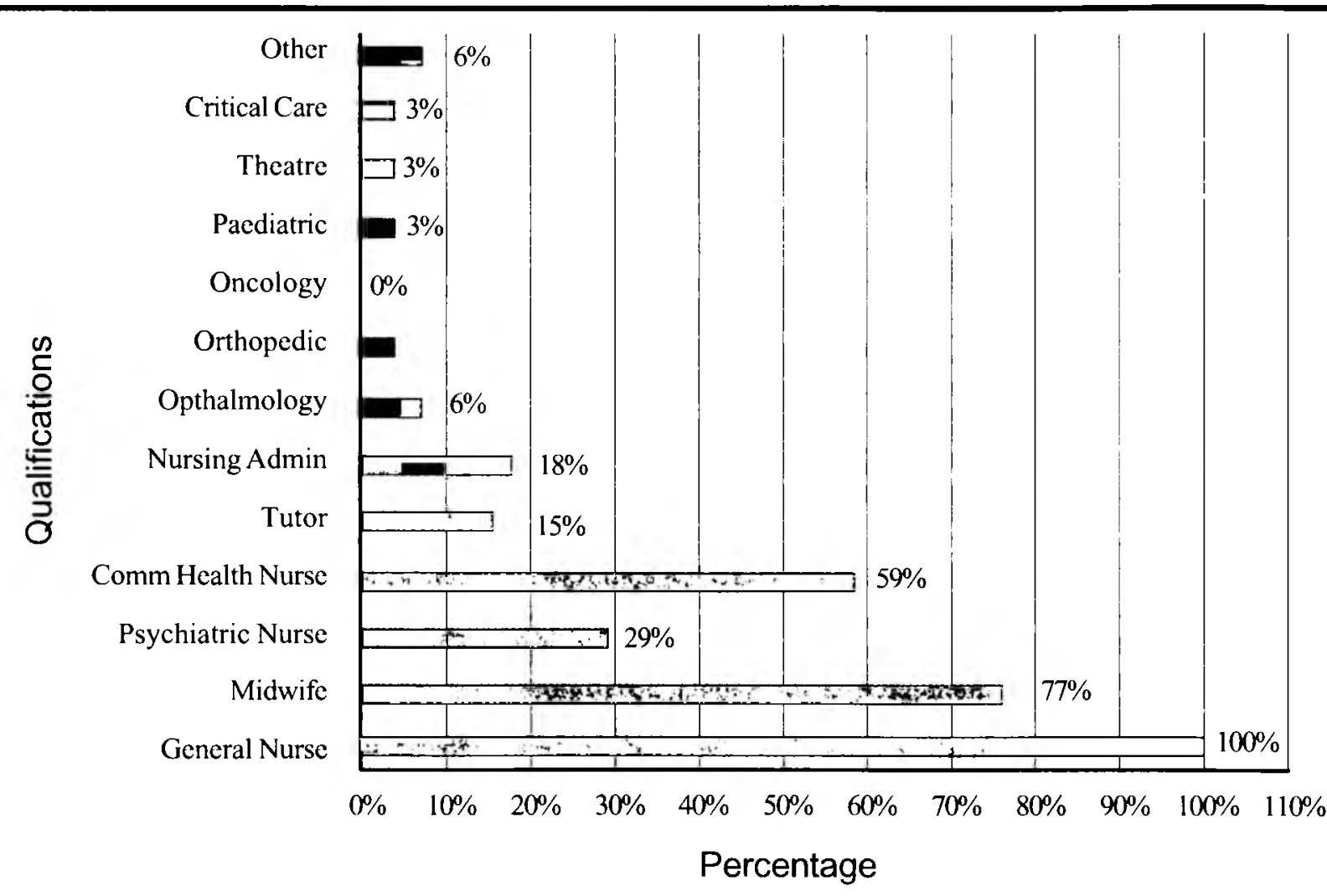




\begin{tabular}{|l|c|c|c|c|}
\hline $\begin{array}{l}\text { ASPECTS REGARDING } \\
\text { WORKING CONDITIONS }\end{array}$ & $\begin{array}{c}\text { EXIREMELY } \\
\text { DISSATISFIED }\end{array}$ & DISSATISFIED & SATISFIED & $\begin{array}{c}\text { EXTREMELY } \\
\text { SATISFIED }\end{array}$ \\
\hline Mission and purpose of the hospital & $1(3 \%)$ & $8(23 \%)$ & $19(56 \%)$ & $6(18 \%)$ \\
\hline $\begin{array}{l}\text { Opportunity to have variety in the } \\
\text { work }\end{array}$ & $5(15 \%)$ & $9(27 \%)$ & $19(55 \%)$ & $1(3 \%)$ \\
\hline Satisfaction with the workload & $20(58 \%)$ & $8(24 \%)$ & $5(15 \%)$ & $1(3 \%)$ \\
\hline Helpfulness of other workers & $3(9 \%)$ & $13(38 \%)$ & $15(44 \%)$ & $3(9 \%)$ \\
\hline Feeling part of the team & $2(6 \%)$ & $11(32 \%)$ & $18(53 \%)$ & $3(9 \%)$ \\
\hline Physical environment & $3(9 \%)$ & $14(41 \%)$ & $15(44 \%)$ & $2(6 \%)$ \\
\hline
\end{tabular}

participants had to cope with multiple demands of being full time employed and the chores of being a wife and mother. As nursing in a hospital requires 24-hour service coverage, thereby requiring of the nurses to also do night duty, the marital status of the participants could have a negative impact on their personal lives, thus leading to frustration and lower job satisfaction.

\section{Hours of work per week}

Although a 40 hour work week applies in the selected community hospital where the research was conducted, 3 participants indicated that they work longer hours.

\section{Experience in nursing}

The majority of the participants $(76 \%$ of 34 participants) was older than 35 years and thus had had at the time of the research a vast experience in nursing. Ten participants had more than 20 years experience in nursing.

\section{Qualifications of the participants}

The qualifications of the participants ranged from general nursing (the whole group) to midwifery (77\% of 34 participants); community health nursing (59\% of 34 participants); psychiatric nursing ( $29 \%$ of 34 participants); nursing management ( $18 \%$ of 34 participants); nursing education $(15 \%$ of 34 participants); to other clinical post-basic qualifications as reflected in Figure 1. The small number of nurses with specialized knowledge in clinical areas of nursing such as advanced midwifery, neonatal and pediatric nursing is due to the shortage of nurses. Study leave could not have been granted due to staff shortages to enable nurses to attend clinical courses as the latter are presented as full time courses. To the frustration of the nurses with clinical post-basic qualifications they were not always allowed to work in the fields of specialization because of shortages of staff in other sections. The nurses had to work where they were needed, irrespective of their expertise. Although $18 \%$ of the nurses $(n=34)$ had post-basic qualifications in nursing. management (Refer to Figure 1) they were not allowed to take responsibility for very basic managerial functions such as leave arrangements and off-duty schedules. All nursing management activities had been centralized; an arrangement that the nurses were frustrated with.

\section{Satisfaction/Dissatisfaction with working conditions in the hospital}

The working conditions in the hospital included the mission and purpose of the hospital; opportunities for variety in the work; satisfaction with the workload; helpfulness of others; fecling part of the team and the physical environment of the hospital.

The participants were relatively satisfied with the mission and purpose of the hospital as the majority indicated that they were either satisfied $(56 \%$ of 34 participants) or extremely satisfied (18\% of 34 participants) with it (Refer to Table 1). Fourteen nurses, that represents approximately one third of the participants, were dissatisfied with the variety in their work activities and it thus needs attention (Refer to Table 1). This result could indicate that the participants feel they were not given adequate autonomy in their work. The continuous shifting of personnel to different wards does not create variety in the activities expected of them and as Humphries and Turner (1989:300-301) point out, an interesting work environment does rank high on the job satisfaction scale.

Twenty-eight participants that represent $82 \%$ of the group $(n=34)$ were dissatisfied with the workload (Refer to Table 1). They considered the workload as too heavy; an obvious reason for the resignation of staff (Bester et al. 1997:59).

As nursing is a team effort, nurses are dependent on each other's helpfulness. If this is lacking it will impact negatively on job satisfaction as it will also influence each person's workload. In the study $47 \%$ ( 16 of 34 participants) of the participants were not satisfied with the helpfulness of co-workers (Refer to Table 1). A possible explanation for nurses not being helpful to colleagues is the heavy workload that they had to cope with. They didn't have the time or inclination to still help others.

Surprisingly the participants were relatively satisfied with being part of a team as 21 (62\% of 34 participants) reported that they were satisfied with feeling part of the team (Refer to Table 1). Apparently the participants were more dissatisfied with the heavy workload and the resultant lack of support that they got from colleagues who were also overworked than with belonging to a team and the general functioning of the team. 


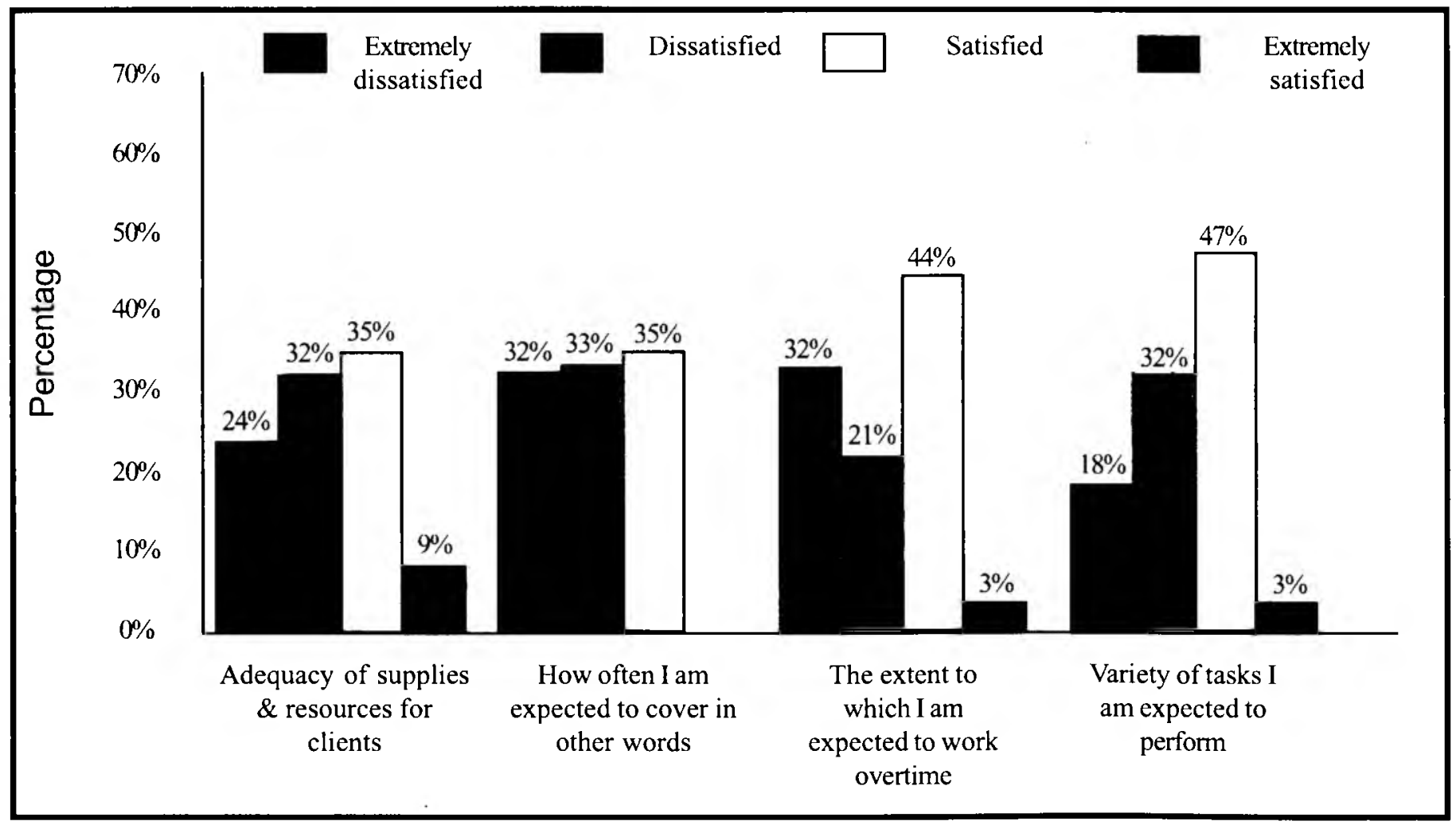

The responses related to the satisfaction/ dissatisfaction with the physical environment were split in a 50:50 relationship. Half of the participants were satisfied with it, while the other half was dissatisfied with the physical environment (Refer to Table 1). It is, however, important to take cognizance of the fact that a motivating environment does not refer to lighting and temperature, but is about acknowledgement of contribution and supportive colleagues (Salvatore-Magalhaes, 1999:65).

Patient care related factors in the working conditions

The satisfaction/dissatisfaction of the participants regarding supplies and resources; the necessity to work in other wards in the absence of enough staff; the frequency of having to work overtime; and the variety of tasks expected of nurses was the focus of this section.

Approximately half of the participants (56\%) were dissatisfied with the adequacy of supplies (Refer to Figure 2). They considered the supplies available to them as insufficient to render effective patient care. Shader et al. (2001:215) pointed out that adequacy of supplies is a significant contributory factor to job satisfaction as it enables nurses to carry out their responsibility towards patients.
Without adequate supplies nurses have to improvise, which is time consuming and adds to an already heavy workload.

Having had to cover for other wards was a thorn in the participants' side as $65 \%$ of them $(n=34)$ were not satisfied with the arrangement (Refer to Figure 2). More than half of the group (53\% of 34 participants) was also dissatisfied with the expectation from management that they had to work overtime (Refer to Figure 2). The participants were not paid for the overtime, but were given the time that they had work overtime back, at a later stage. The results of a study by Fletcher (2001:327) also indicated that participants complain about a lack of consideration for family relationships when they were required to work overtime.

\section{Personal factors in the working conditions}

Personal factors that have an influence on the employee's satisfaction with working conditions include opportunities for personal growth; challenges associated with the job; and the guidance provided by supervisors. The amount of personal growth and development showed a greater level of job dissatisfaction as $54 \%$ of the participants $(n=34)$ indicated that they were either dissatisfied $(45 \%)$ or extremely dissatisfied (9\%) with it (Refer to Figure 3 ). This could probably mean that there was not adequate in-service training on aspects that are of interest to them, or possibly due to staff shortages that made it impossible for them to further their studies. Staff development is considered to be essential in maintaining a sense of competence (Watson, 2002:23) and personal growth of employees. The proposed compulsory continuing professional development to be introduced by the South African Nursing Council, could help to improve this situation (SANC, 2002:1).

The statement on the "overall supervision my supervisor provides" showed a $68 \%$ level of dissatisfaction with the amount and/or type of supervision $(n=34)$ (Refer to Figure 3 ). The participants' complaints could either relate to too strict supervision with fewer opportunities for personal growth through experiential learning ( $54 \%$ of the 34 participants were dissatisfied with the amount of personal growth) or to not enough supervision. The latter could relate to the high percentage of the participants ( $61 \%$ of 34 ) that found their jobs challenging (Refer to Figure 3 ).

\section{Post-related factors in the working conditions}

The way in which an institution treats its 


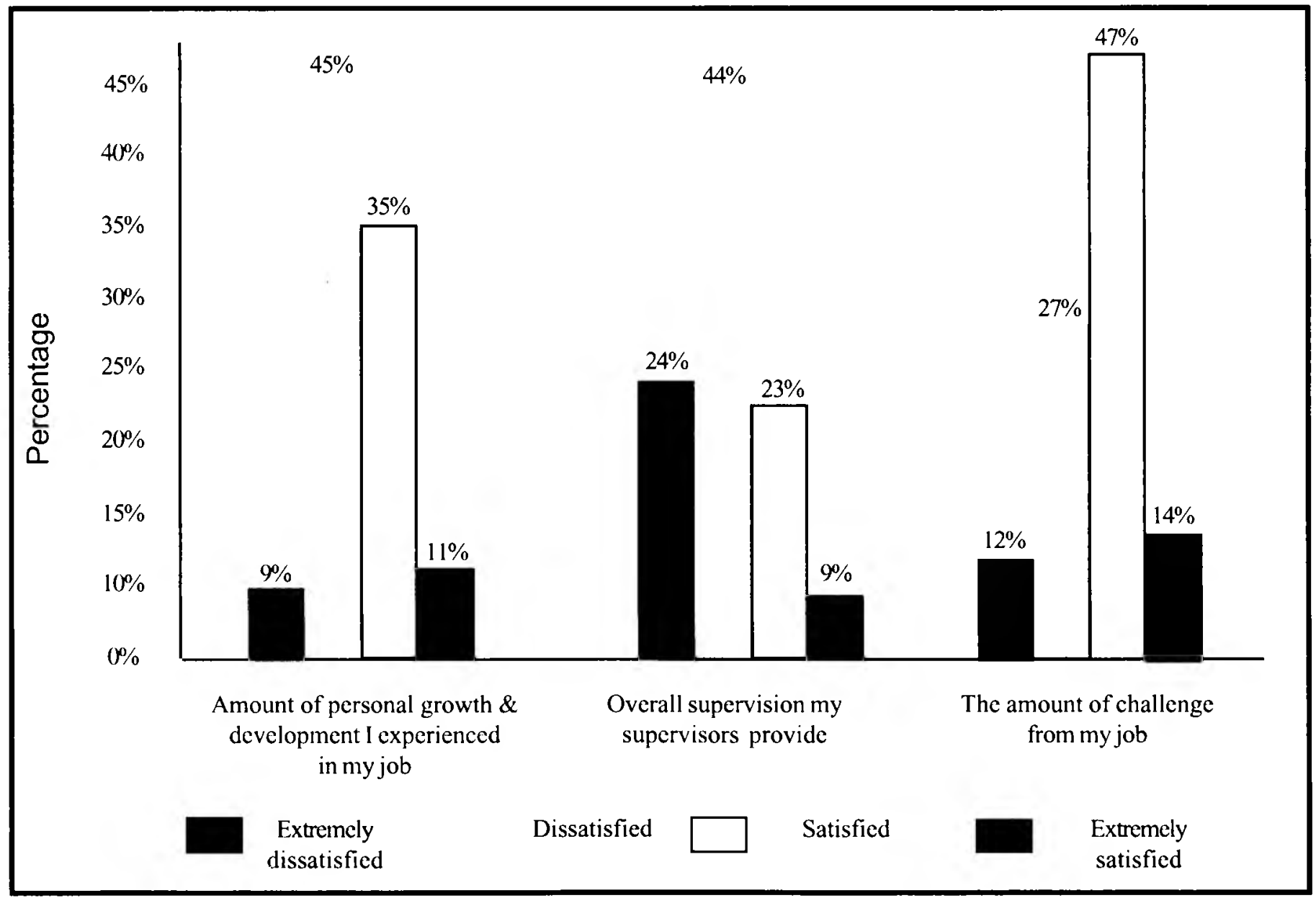

employees; the amount of job security that the staff experiences; the pay and fringe benefits; and the degree of fair payment in relations to inputs from the staff are all post-related factors that impact on job satisfaction.

The fact that $80 \%$ of the participants were dissatisfied about post-related factors (Refer to Figure 4) could probably be that they perceived the treatment they received as being unacceptable as they had been expected to work overtime, while the general workload was already heavy. According to Adam and Bond (2000:541) staff experience job dissatisfaction when they get the feeling that their supervisors devalue their work and do not attend to their concerns appropriately. The participants in this study perceive the management of the hospital not to be supportive.

Slightly more than half of the participants (53\% of 34 ) were satisfied about their job security (Refer to Figure 4). This is due to the majority of the participants already having had more than 16 years of service already. They had thus already experienced job security. Fletcher (2001:325) does, however, note that restructuring of personnel introduces uncertainty, something that is presently taking place in the public healthcare sector in South Africa (Geyer, 2001 :26).

By far the majority of the participants (79\% of 34 ) werc dissatisfied with their pay and fringe benefits. The majority of the participants were also either dissatisfied with their payment in relation to their job inputs $(41 \%)$ or extremely dissatisfied $(38 \%)$ with their remuneration (Refer to Figure 4).

\section{Emotional climate}

The emotional climate in the hospital referred for the purpose of this study to rendering of holistic patient care; performing preferred tasks; cooperation from co-workers; morale in the units; improving work methods; job interest; opportunities to express doubt about delegated duties; appreciation of opinions of the staff; experiences of acknowledgement; values of selfesteem; and opportunities for development.

Nurses experiencing a shortage of staff, leading to increased work pressure as a result of the workload, often need the support and appreciation of supervisors as well as cooperation and acceptance of co-workers. This is echoed by Fletcher (2001:328), who states that being overworked is not as great a stressor if the work environment is good.

Nursing has always been about a holistic approach, of seeing the patient in totality. Nurses therefore prefer to nurse patients in totality instead of compartmentalizing patient care. Twenty participants $(59 \%$ of 34) in this study were satisfied that they were able to render total patient care (Refer to Table 2). This unfortunately also means that 14 nurses were dissatisfied with the situation. It could be that the shortage of nurses and the heavy workload forced them to relate to the functional or task oriented approach in nursing care delivery.

Ten participants $(30 \%$ of 34$)$ expressed their dissatisfaction with not being allowed to perform the tasks that they preferred (Refer to Table 2). This could either be related to the functional approach in nursing care or the lack of opportunities to work in the ward of choice. Hertzberg as cited by McCoy (1999:43) noted that job satisfaction is 


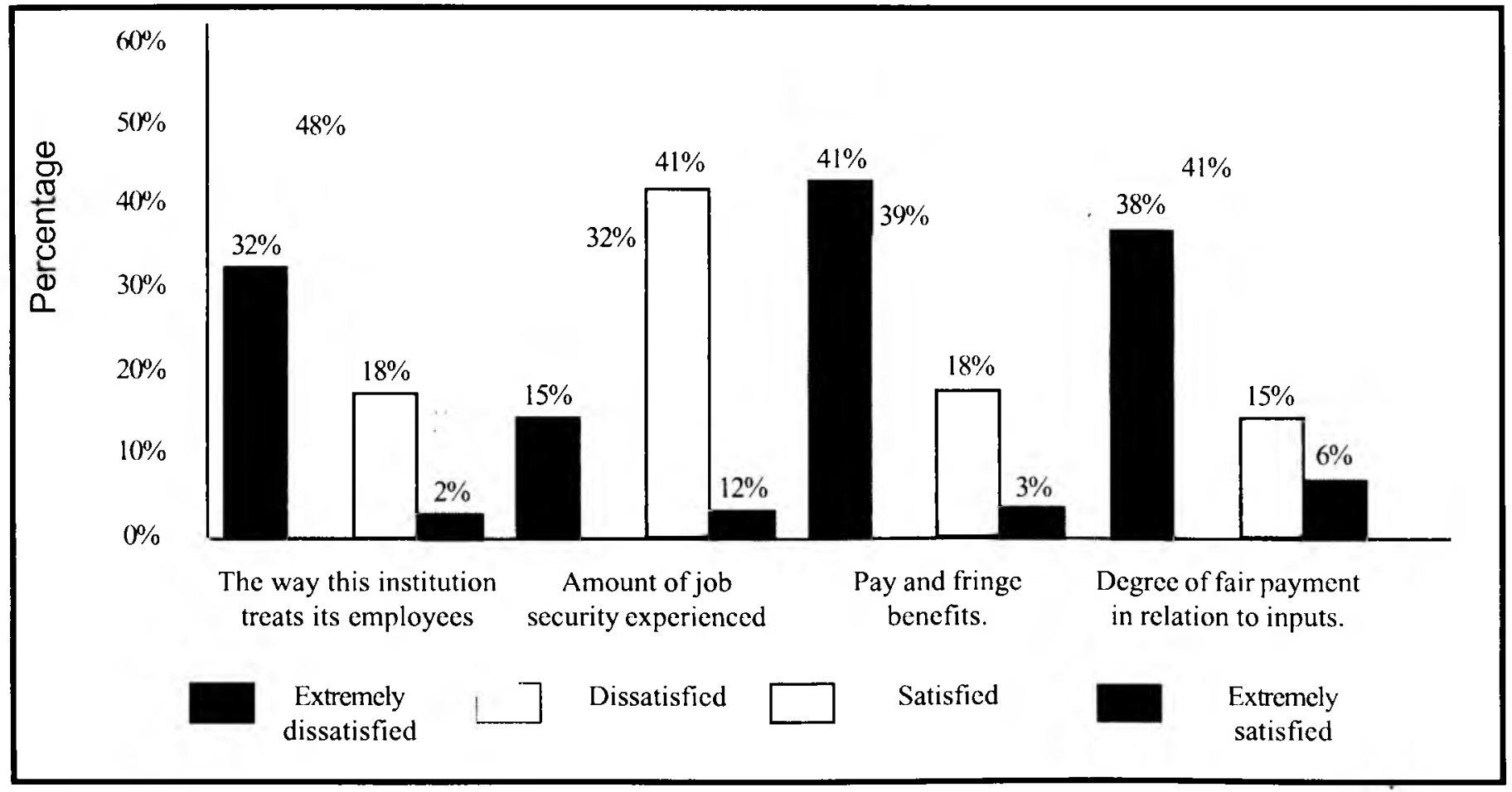

Table 2: Satisfaction / dissatisfaction with emotional working climate $(n=34)$

\begin{tabular}{|lcccc|}
\hline $\begin{array}{l}\text { ASPECTSREGARDING } \\
\text { EMOTIONAL WORKING } \\
\text { CLMATE }\end{array}$ & $\begin{array}{c}\text { EXIREMFIY } \\
\text { DISSATISFIED }\end{array}$ & DISSATISFIED & SATISFIED & $\begin{array}{c}\text { EXIREMHIY } \\
\text { SATISFIED }\end{array}$ \\
\hline Rendering of total patient care & $4(12 \%)$ & $10(29 \%)$ & $15(44 \%)$ & $5(15 \%)$ \\
\hline Performing preferred tasks & $3(9 \%)$ & $7(21 \%)$ & $19(56 \%)$ & $5(15 \%)$ \\
\hline Cooperation from co-workers & $3(9 \%)$ & $10(29 \%)$ & $14(41 \%)$ & $7(21 \%)$ \\
\hline Morale in the units & $5(15 \%)$ & $12(35 \%)$ & $16(47 \%)$ & $1(3 \%)$ \\
\hline Improving work methods & $3(9) \%$ & $18(53 \%)$ & $13(38 \%)$ & $0(0 \%)$ \\
\hline Job interest & $1(3 \%)$ & $5(15 \%)$ & $16(47 \%)$ & $12(35 \%)$ \\
\hline $\begin{array}{l}\text { Expression of doubt } \\
\text { delegated duties }\end{array}$ & $6(18 \%)$ & $11(32 \%)$ & $14(41 \%)$ & $3(9 \%)$ \\
\hline $\begin{array}{l}\text { How much their opinion secms to } \\
\text { count }\end{array}$ & $4(12 \%)$ & $11(32 \%)$ & $17(50 \%)$ & $2(6 \%)$ \\
\hline
\end{tabular}

enhanced when nurses are allowed to work in the particular area of interest.

Cooperation from co-workers promotes good working relationships and increases satisfaction even under conditions of increased work pressure. In the study conducted by Humphries and Turner (1989:304) cooperation has been ranked prominently on top on the emotional climate satisfaction scale as being the most important aspect that contributes to job satisfaction. In this study 21 participants $(63 \%$ of 34$)$ were satisfied with the spirit of cooperation between co-workers in the hospital (Refer to Table 2 ). It correlates with the number of participants that were satisficd with the helpfulness of colleagues in Table 1. It also correlates with the morale in the units (micro-environment) as $50 \%$ of the participants $(n=34)$ were satisfied with the latter (Refer to Table 2). The cooperation that they got from co-workers contributed to the relatively good morale.

In order to promote job satisfaction, nurses should be involved in designing the care delivery models (Watson, 2002:230). As 21 participants (62\% of 34 ) were dissatisfied with them not having been involved in improving the work methods in the hospital (Refer to Table 


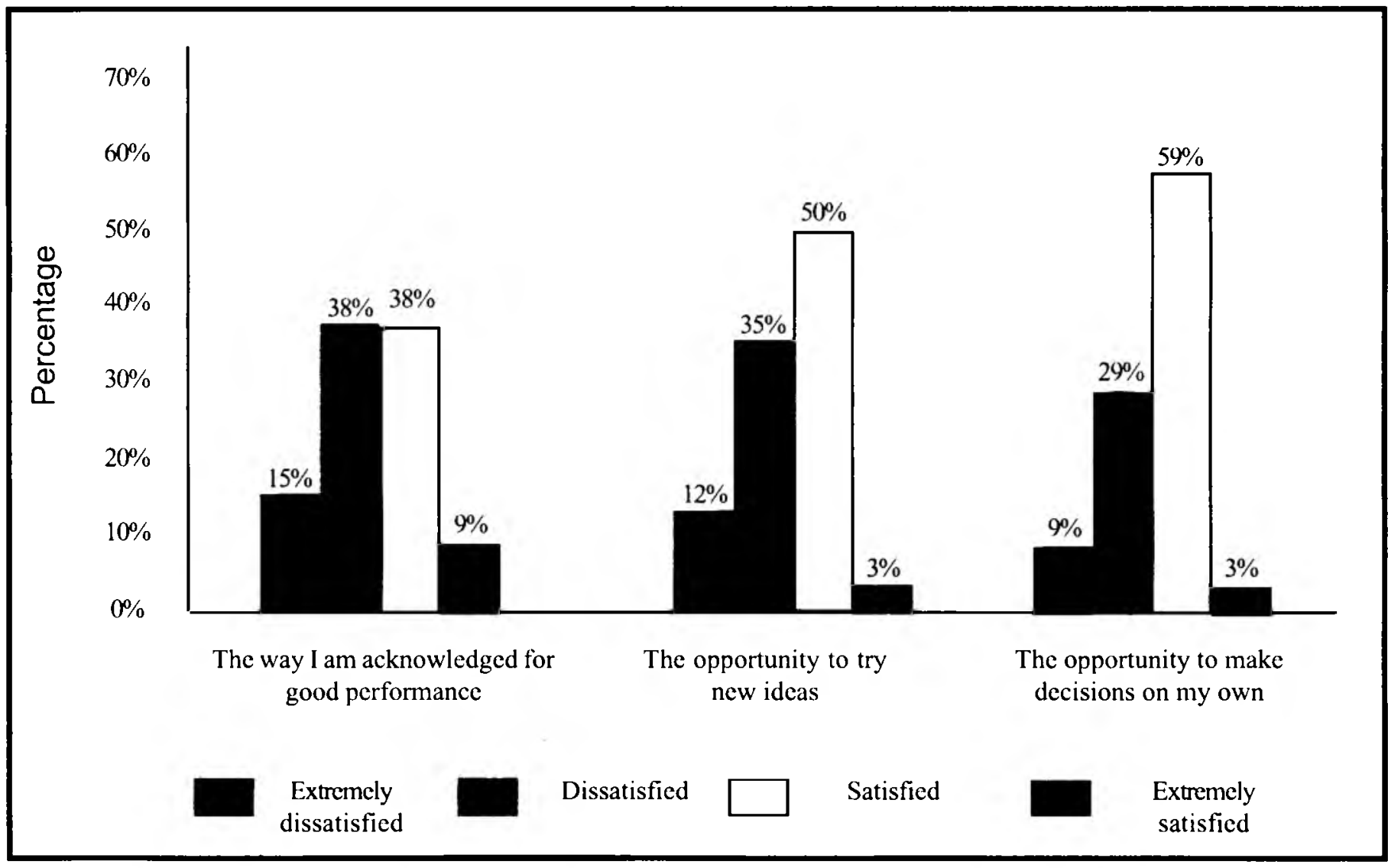

2), it can be assumed that this deficiency contributed to the job dissatisfaction of nurses in the hospital where this study was conducted.

Although the nurses had to work under difficult circumstances (heavy workload, not being allocated to wards of choice and not enough opportunities to develop and grow), the majority of them ( $82 \%$ of 34 participants) still indicated that they were interested in nursing as career opportunity (Refer to Table 2).

Nurses in general value the opportunity and freedom to express their doubt about delegated duties should they not agree with them. Exactly half of the participants (17) were dissatisfied with the situation in the hospital (Refer to Table 2). About half of them (44\% of 34 participants) indicated that they were also dissatisfied with how much their opinion seemed to count at work (Refer to Table 2).

The fact that acknowledgement of good performance was rated slightly higher (53\% of 34 participants) on the dissatisfaction level (Refer to Figure 5) could most probably be due to the fact that performance evaluations had not been done in the year preceding the research. The participants might have felt that their contributions to patient care had not been appreciated. McCoy (1999:41) emphasizes that a top motivator for employee performance is recognition for a job well done.

As the participants had worked in different wards and under supervision of different managers, their satisfaction/ dissatisfaction with the opportunity to try new ideas were almost equal on both satisfaction and dissatisfaction levels (Refer to Figure 5). The participants rated the variable "opportunity to make decisions on my own" higher $(61 \%$ of 34 participants) on the satisfaction level (Refer to Figure 5). Autonomy and the opportunity to make decisions on his/ her own are considered to be a good predictor of job satisfaction (Bester et al. 1997:61).

Figure 6 shows that a high percentage of dissatisfaction on the aspect of pressure of work ( $82 \%$ of 34 participants) was experienced. This aspect is related to "workload" under "working conditions", which also has an $82 \% \quad(n=43)$ dissatisfaction level (Refer to Table 1). These aspects are probably caused by the problem of staff shortages. In cases where staff experience supervisors as detached from the problem frustration and dissatisfaction are present. Where supervisors promote teamwork amongst staff and support staff pressure of work due to workload is less felt.

According to the scores on satisfaction and dissatisfaction with "the degree of respect from my supervisor" it is indicated that the relationships between the nurses and their unit managers differed as $44 \%$ of the participants $(n=34)$ were dissatisfied with the situation while $56 \%(n=34)$ were satisfied (Refer to Figure $6)$. The majority of the participants $(85 \%$ of 34) were satisfied with the self-esteem that they experienced in the work that they were doing.

The variable "The opportunity I have to learn and develop in the past year" shows an equal percentage on satisfaction ( $50 \%$ of 34 participants) and dissatisfaction (50\% of 34 participants) (Refer to Figure 7). The opportunity to attend formal courses offered by a university or college has however been difficult to implement because of not being able to send staff on study leave in reasonable numbers.

Responses to "Whether someone at work discussed my progress with me in the past year" show a high percentage on the extreme dissatisfaction level $(30 \%$ of 34 participants) (Refer to Figure 7). 


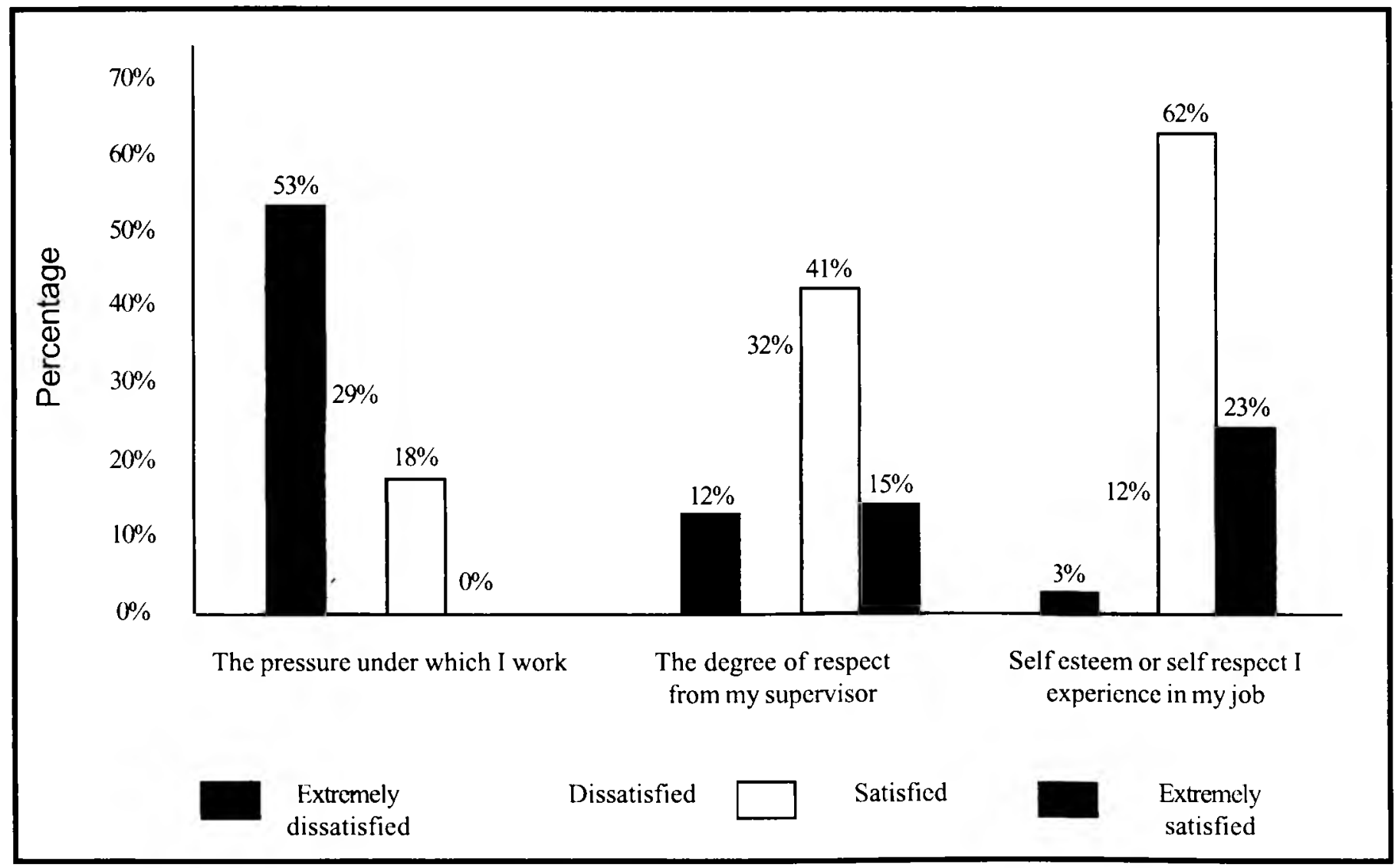

The participants' responses to "The degree of fair treatment from my supervisor", also indicate dissatisfaction (38\% of 34 participants) and extreme dissatisfaction ( $21 \%$ of 34 participants) (Refer to Figure 7) thus reflecting the probability of strained relationships between most employees and their supervisors.

\section{Social climate at work}

The social climate at work referred in this study to the attitudes of colleagues; opportunities to get to know other people at the job; commitment of fellow employees to quality work; support from colleagues and supervisors; chances to help other people; and scheduling of work shifts.

As the participants spent at least 40 hours per week at work, the supportive interaction with co-workers and supervisors could provide a much needed support system to the nurses. This was the case as the participants communicated their satisfaction $(50 \%$ of the participants) and even extreme satisfaction ( $24 \%$ of the participants) with the attitudes of their co-workers that they talked to and worked with in their units (Refer to Table 3). The majority ( $73 \%$ of the participants) also expressed their satisfaction with their fellow employees' commitment to quality work.

It is thus no surprise that 28 participants $(82 \%$ of 34$)$ were satisficd with "getting to know the other people on the job" (Refer to Table 3). This emphasizes the importance of taking an interest in ensuring a caring environment for nurses at work (Atchison, 1998:137).

A poor interpersonal relationship between supervisors and employees was reflected in the high percentage of the participants $(62 \%$ of 34$)$ that indicated that they were not satisfied with the guidance provided by their supervisors (Refer to Table 3). This is in contrast to the 21 participants $(61 \%$ of 34 ) who had someone at work who encouraged them and the 26 participants ( $76 \%$ of 34 ) who commented on the chances that they had to help other people while at work (Refer to Table 3). The latter supports the importance of good teamwork which could serve as a counterbalance to the problems caused by staff shortages (Tovey \& Adams, 1999:152).

The opinions on "the practical guidance received from other staff" reflected that 15 participants $(44 \%$ of 34 ) were dissatisfied with the practical guidance that they received from other staff. Both the other two items received strong positive responses (Refer to Figure 8).

The positive response $(59 \%$ of 34 participants) to "my off-duty requests are considered' and "I am allowed time off when one of my family members is ill" (77\% of 34 participants) indicates some satisfaction with off-duty requests (Refer to Figure 9). Satisfaction with off-duty requests and time off allowed for illness of a family member do relate to employee satisfaction (Tovey \& Adams (2000:542). Sixty-five percent of the participants were satisfied with the opportunities to socialize and communicate with colleagues at work (Refer to Figure 9).

\section{Conclusion}

More than $60 \%$ of the participants were dissatisfied with:

- The high workload, including the pressure under which they had to work, and that they had to cover in other wards because of staff shortages;

- $\quad$ The way that they were treated by the hospital management including inadequate supervision and support from supervisors and lack of 


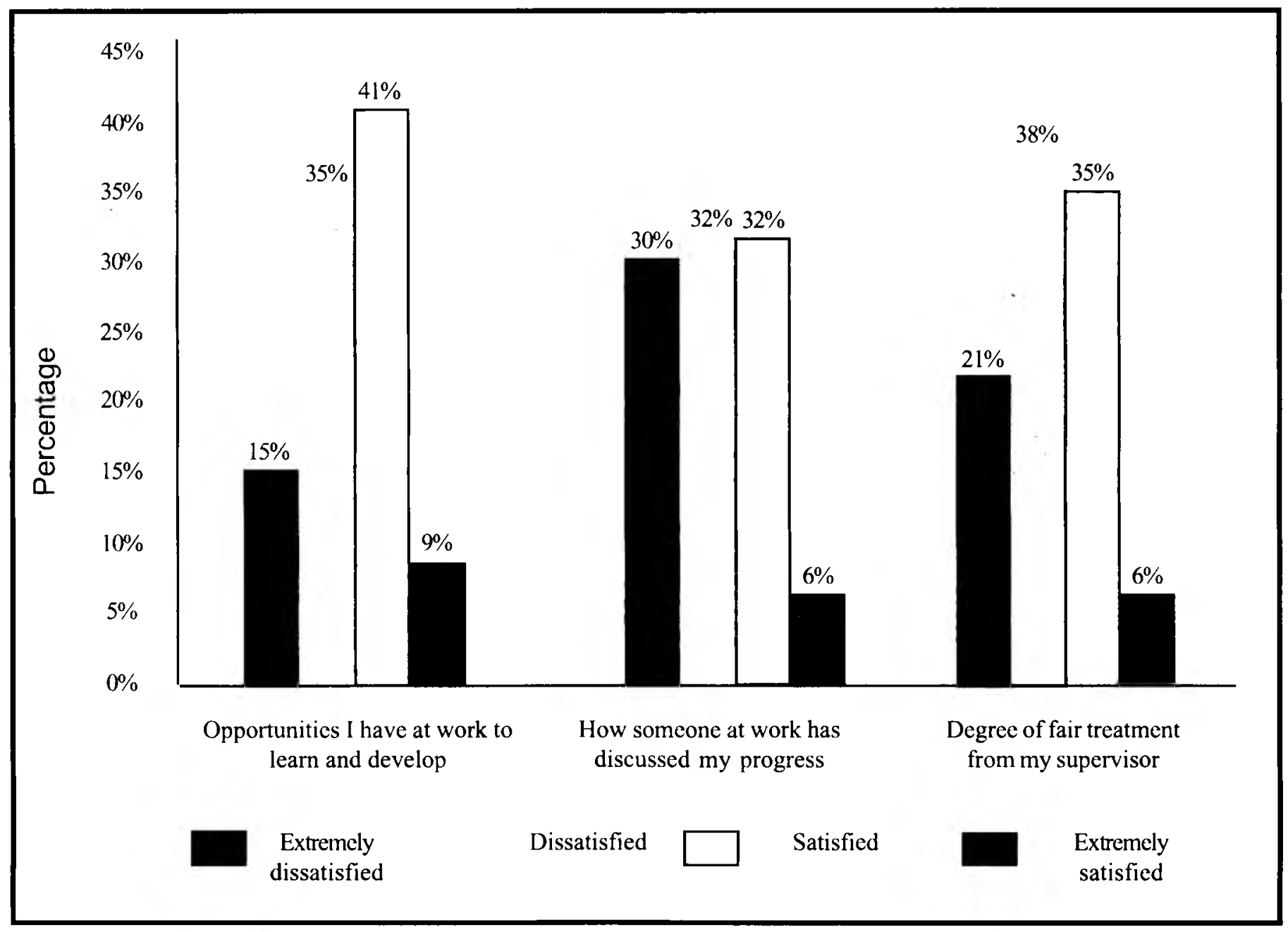

Table 3: Satisfaction / dissatisfaction with social working climate $(n=34)$

\begin{tabular}{|lcccc|}
\hline $\begin{array}{l}\text { ASPECTSOF SOCIAL WORKING } \\
\text { CIMATE }\end{array}$ & $\begin{array}{c}\text { EXIREMELY } \\
\text { DISSATISFIED }\end{array}$ & DISSATISFIED & SATISFIED & $\begin{array}{c}\text { EXIREMELY } \\
\text { SATISFIED }\end{array}$ \\
\hline Attitudes of colleagues & $1(3 \%)$ & $8(24 \%)$ & $17(50 \%)$ & $8(24 \%)$ \\
\hline Get to know other people at the job & $0(0 \%)$ & $6(18 \%)$ & $22(64 \%)$ & $6(18 \%)$ \\
\hline $\begin{array}{l}\text { Commitment of fellow employees to quality } \\
\text { work }\end{array}$ & $4(12 \%)$ & $5(15 \%)$ & $20(58 \%)$ & $5(15 \%)$ \\
\hline $\begin{array}{l}\text { There is someone at work who encourages } \\
\text { me }\end{array}$ & $4(12 \%)$ & $9(27 \%)$ & $15(44 \%)$ & $6(17 \%)$ \\
\hline $\begin{array}{l}\text { The amount of support provided by } \\
\text { supervisor }\end{array}$ & $10(30 \%)$ & $11(32 \%)$ & $11(32 \%)$ & $2(6 \%)$ \\
\hline \begin{tabular}{l} 
The chance to help other people \\
\hline
\end{tabular} & $1(3 \%)$ & $7(21 \%)$ & $19(55 \%)$ & $7(21 \%)$ \\
\hline
\end{tabular}

performance appraisals; Poor pay and fringe benefits and specifically their payment in relation to the inputs that they had to make; and

- Lack of opportunity to be involved in improving the work methods in the hospital.

The main sources of satisfaction were related to interpersonal relationships and their interest in nursing as a profession. More than $60 \%$ of the participants were satisfied with:
The mission and vision of the hospital as an institution that renders patient care;

Their experiences as part of a team, support and cooperation from co-workers, and the commitment of the team to 


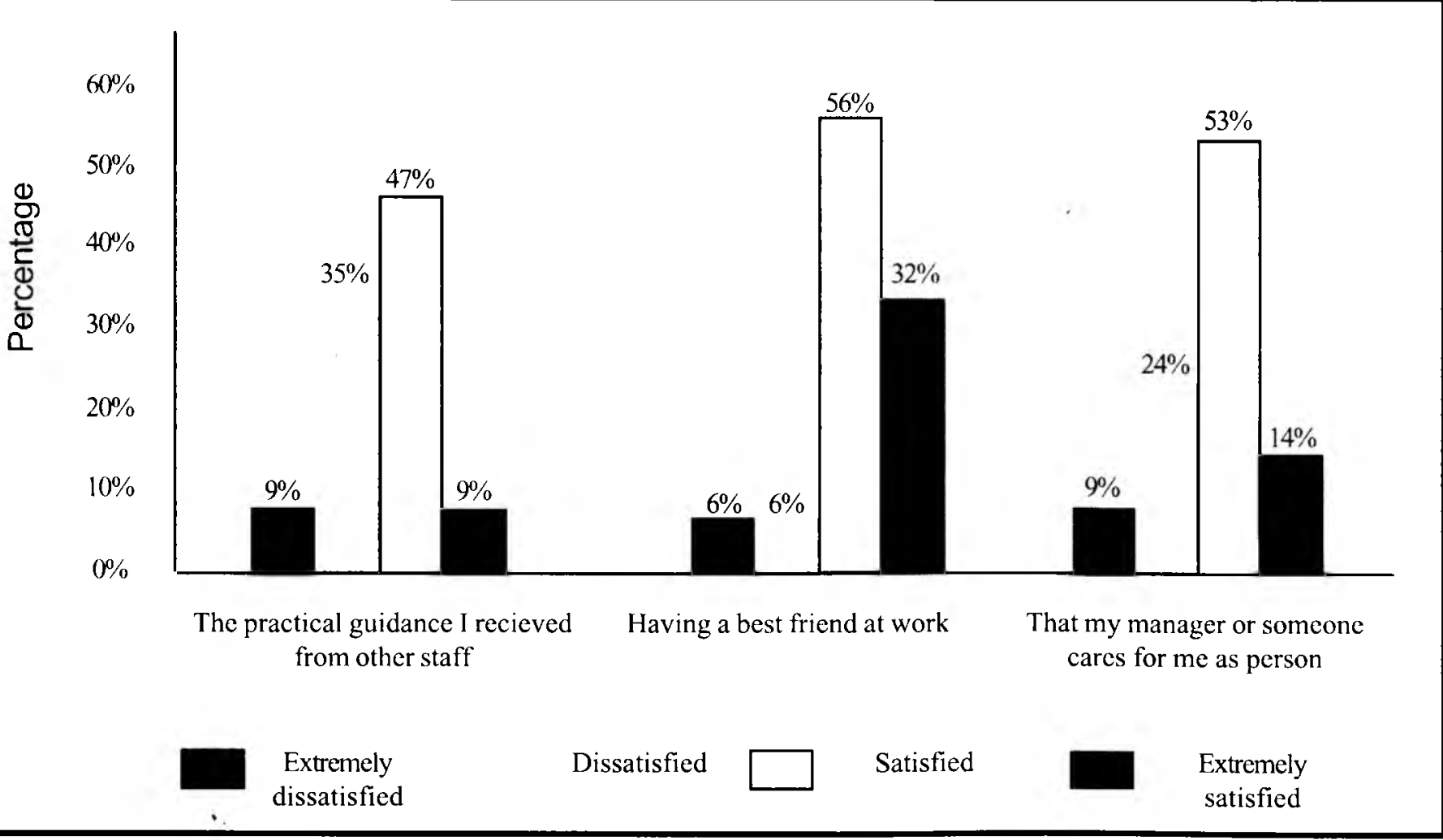

quality work;

- The opportunity to get to know other people at work, and the chance to socialize and communicate with colleagues at work;

- Colleagues who became 'best friends' and the caring attitude towards their colleagues at work:

- The opportunities to be granted time off when family members were sick;

- The chance to help other people (patients);

- Their interest in nursing, including their self-respect as nurses and the opportunity to make decisions about the care of patients on their own; and

- The amount of challenges in their jobs and opportunities to perform preferred tasks.

\section{Recommendations}

The main recommendation is the development of an employee assistance programme to promote the retention of dedicated nursing staff in the hospital. The programme should focus on addressing the areas of dissatisfaction and the promotion of the aspects that the staff is satisfied with. The allocation of a reasonable workload and the reduction of the pressure that the staff has to endure are recommended. The managers have to be willing to buffer the stress through continuous support and visibility in the wards.

Mangers need to involve the nurses in decisions on scheduling so that nurses are allowed to determine schedules reflecting their own preference. Greater participation of unit managers in the management of nursing care and the improving of work methods in wards and units should be encouraged.

Nurse managers also need to understand the characteristics and work ethics of the different generations (such as Baby Boomers and Generation X'ers) in order to plan their involvement in decision making, opportunities for further studies and ultimately to retain the nursing work force.

Acknowledgement of employees by nurse mangers should be emphasized. Giving due recognition for a job well done, and no-cost rewards like writing a letter to the employees to compliment them on good work, are examples of gestures that would do a great deal to promote selfesteem and job satisfaction. Performance appraisal should also be encouraged among supervisors and the importance of the regularity and consistency of the appraisals should be emphasized.

\section{Summary}

Although the nurses of the selected community hospital were very dissatisfied with their working conditions and more specifically with the poor relationship between them and their supervisors, many of them were still very proud of being nurses. The good interpersonal relationship with their coworkers enabled them to keep on rendering a service to the community.

\section{References}

ADAM, S \& BOND, S 2000: Hospital nurses' job satisfaction, individual and organizational characteristics. Journal of Advanced Nursing, 32(3):536-543.

ATCHISON, JH 1998: Perceived job satisfaction factors of nursing assistants employed in Midwest nursing homes. Geriatric Nursing, 9(3):135-138.

BESTER, CL; RICHTER, EC \& BOSHOFF, AB 1997: Prediction of nurses job satisfaction level. Curationis, 20(4):59-63.

FLETCHER, CE 2001: Hospital RNS' job satisfaction and dissatisfactions. JONA, 31(6):324-330.

GEYER, N 2001: The migration of nurses and midwives. Nursing Update, 25(10):26-27. 


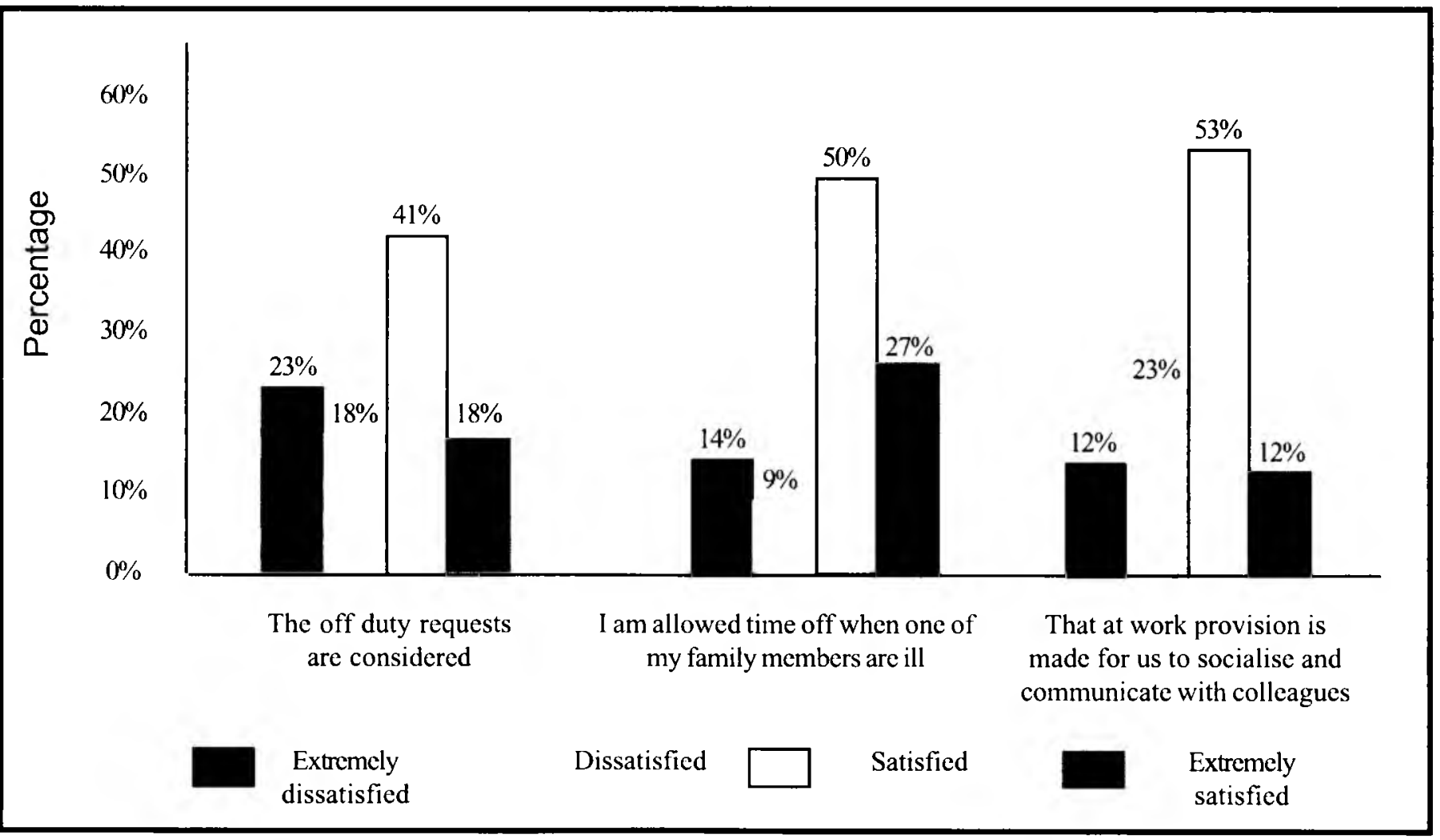

HUMPHRIES, GM \& TURNER, A 1989:

Job satisfaction and attitudes of nursing staff on a unit for the elderly severely mentally infirm with change of location. Journal of Advanced Nursing, 14(4):278307.

KUPPERSCHMIDT, BR 2001: Understanding Net Generation employees. JONA, 31(12):570-574.

McCOY, JM 1999: Recognise, reward, retain. Nursing Management. February 1999:41-43.

SALVATORE-MAGALHAES, J 1999: Remember where you came from. Nursing Management, May 1999:29-30.

SHADER, S; BROOME, E; BROOME, CD; WEST, ME \& NASH, M 2001: Satisfaction and anticipated turnover in nurses in an academic medical centre. JONA, 31(4):210-216.

\section{SOUTH AFRICAN NURSING} COUNCIL, 2002: A system of continuing professional development for nurses and midwives in South Africa. Draft document.

TOVEY, EJ \& ADAMS, AE 1999: The changing nature of nurses' job satisfaction. An exploration of sources of satisfaction in the 1990s. Journal of Advanced Nursing, 31(1):150-158.
WATSON, CA 2002: Understanding factors that influence nurses' job satisfaction. JONA, 32(5):229-231. 